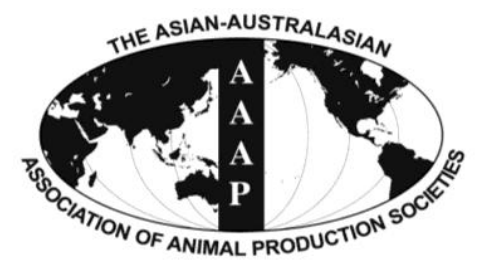

Asian Australas. J. Anim. Sci.

Vol. 26, No. 10 : 1496-1503 October 2013

http://dx.doi.org/10.5713/ajas.2013.13137

www.ajas.info

pISSN 1011-2367 elSSN 1976-5517

\title{
Influence of Municipal Abattoir Conditions and Animal-related Factors on Avoidance-related Behaviour, Bleeding Times at Slaughter and the Quality of Lamb Meat
}

\author{
Yonela Z. Njisane and Voster Muchenje* \\ Department of Livestock and Pasture Science, University of Fort Hare, P. Bag x1314, Alice 5700, South Africa
}

\begin{abstract}
The objective of this study was to determine the effect of municipal abattoir conditions and animal factors on avoidance-related behaviour (AB) of sheep at slaughter, bleeding times (BT) and mutton quality. The behaviour of 66 castrates and 19 ewes of different age categories was observed at three stages of slaughter. Higher behaviour scores indicated higher levels of AB. Time intervals between the start of blood flow and the time the flow changed from a constant stream into drips were recorded as BT. Thirty two meat samples were obtained to measure quality variables. These were colour ( $\mathrm{L}^{*}, \mathrm{a}^{*}$ and $\left.\mathrm{b}^{*}\right), \mathrm{pH}_{24}$, temperature, cooking loss (CL) and tenderness. Correlations were determined between BT and meat quality variables. Animal behaviour at slaughter differed with breed, gender and age group. Avoidance behaviour was higher in the Dorper breed than in both the Merino breed and their crosses. It was also higher in younger ( $<10$ months) lambs than in older sheep. Castrates were more aggressive or in panic than ewes. Castrates had longer (72.6 $\pm 0.53 \mathrm{~s}) \mathrm{BT}$ than the ewes $(63.6 \pm 2.82 \mathrm{~s})$. Ewes had higher CL $(39.8 \pm 1.04 \%)$ values than castrates $(35.1 \pm 0.95 \%)$. Meat from castrates was tougher $(32.6 \pm 1.95 \mathrm{~N})$ than the meat from ewes $(24.3 \pm 1.16 \mathrm{~N})$. There were no significant correlations obtained between BT and meat quality variables. It can therefore be concluded that abattoir conditions, breed, age and gender had an effect on AB at slaughter. Gender had an effect on BT and mutton quality. (Key Words: Exsanguination, Mutton, Animal Characteristics, Slaughter House)
\end{abstract}

\section{INTRODUCTION}

When handling animals, it is important to remember some general factors that can affect their behaviour, such as the degree of tameness (flight distance), especially towards humans, breed and species, and the type of environment in which the animals are raised (McGreevy, 2003). Hemsworth et al. (1987) provided a better explanation for this phenomenon that behaviours such as avoidance and approach can be used as indices of aversion to a given situation, as fear responses serve to protect animals from aversive stimuli.

Furthermore, sheep are able to differentiate between their handler and a stranger, to the point that the presence of their handler has a calming effect in stressful conditions (Boivin et al., 1997). Markowitz et al. (1998) observed that human feeding and handling of lambs within the first 10 days of their lives resulted in increased affinity for humans

\footnotetext{
* Corresponding Author: Voster Muchenje. Tel: +27-40-6022059, Fax: +27-86-628-2967, E-mail: vmuchenje@ufh.ac.za Submitted Mar. 5, 2013; Accepted May 8, 2013; Revised May 26, 2013
}

later in life. A practical scenario is that of a pasture-based dairy system, wherein dairy cows are out in the pasture all the year round, and human-animal interaction is a daily occurrence during different management procedures (milking, health inspection, etc). This human-animal contact has the potential to affect the cows depending on how the contact was carried out, but it ultimately affects milk production (Dodzi and Muchenje, 2011).

The environmental change from farm to abattoir affects the animals' behaviour. For instance, sheep are reluctant to enter dark areas from lighter areas; in addition any unevenness on the floor can cause sheep to balk (McGreevy, 2003), and they tend to move in the opposite direction to handler movement when confined in yards (Grandin, 2002). Sheep may also be disturbed by slaughter plant odours (Grandin, 1980), and are particularly frightened by sudden loud noise at slaughter plants (McGreevy, 2003) hence it is important to minimise noise as much as possible.

Slaughter technology of food animals became scientifically important only when it was observed that events, which happen from farm to slaughter, had a large 
influence on meat quality (Swatland, 2000). Animal welfare problems are always related to inadequate facilities and equipment, distractions obstructing animal movement, lack of training of personnel, lack of equipment maintenance, and improper handling (Grandin, 1996). It is the abattoir's responsibility to ensure that from the time the animals arrive at the abattoir and are off-loaded, right up until the time of slaughter, the animals are not anxious or stressed as this has a direct effect on the quality of the meat products (RMAA, 2011). Well looked after animals at both farms and slaughter provide better quality meat products. Fear of humans can result in stress and thus decreased health and productivity in farm animals (Breuer et al., 2000; Hemsworth, 2003; Waiblinger et al., 2006) at slaughter where there is high human-animal interaction especially in less commercial abattoirs with little machinery available.

Meat from less intensive but more economically sustainable production regimens is often lower in quality than meat from more intensive systems (Ahnstrom et al., 2012). Research has shown that a better quality meat with a longer shelf life can be produced if animals are handled with greater patience, understanding and care at slaughter (RMAA, 2011). The way the animals are handled to the slaughtered floor can affect the quality of the end product. This is however frequently overlooked, especially in municipal abattoirs where abuses take place as a result of the animals being handled by untrained staff who works with little or no supervision (Ndou et al., 2011; RMAA, 2011). The nature of municipal abattoirs is that they tend to serve a very small market. Their ability to function is mostly dependant on the demand of the surrounding abattoirs, slaughter is normally random. Information on these abattoirs is very limited. Most reported studies have been carried out in well-equipped commercial abattoirs (Jago et al., 1996; Wood et al., 2003; Grandin, 2003; 2006; 2010; Njisane and Muchenje, 2013). Therefore such work is necessary for the industry where assessment will be done based on the practical issues raised as affecting the behaviour, bleeding times and the quality of meat from sheep slaughtered at a municipal abattoir. Inefficiency in bleeding out animals at slaughter deteriorates the meat keeping quality (Roca, 2002).

The objective of the current study was to determine the effect of abattoir conditions, breed, gender and age on avoidance-related behaviour of sheep at slaughter, bleeding times at exsanguination and the quality of mutton produced at a municipal abattoir. Correlations between bleeding times and meat quality variables were also determined.

\section{MATERIALS AND METHODS}

\section{Animal description}

Eighty five sheep of 19 ewes and 66 castrates were used in the current study. The small sample size of slaughter animals was affected by the outbreak of Rift Valley Fever that attacked the Eastern Cape in 2011, which is the period during which the data collection began. The sheep were comprised of 3 different breeds (60 Dorper, 5 polled Merino, and 20 of their Crosses) of age groups 1 ( $<10$ months) and 2 (11 to 12 months). The animals slaughtered were sourced from farms around Adelaide, which are 20 to $30 \mathrm{~km}$ away and records were taken as they arrived for slaughter. Carcass weights of these sheep were also recorded.

\section{Slaughter procedure}

Sheep arrived at the abattoir on the same morning of slaughter. Depending on the sheep numbers, animals were transported by a van $(3.4 \mathrm{~m} \times 4.4 \mathrm{~m})$ and sometimes a trailer would be added when the sheep were more than 10 . The animals had a minimal resting period prior to slaughter. Sheep were driven manually by the abattoir workers from the race through to the slaughter floor. The handler would stand behind the animals directing the to the slaughter floor entrance. Sometimes the handler would tap the sheep on the back making sure they keep moving and this happened rarely as the sheep had no option but to move forward away from the person behind them. One person at the stunning floor would grab the animal into the slaughter house (stunning floor). Three people were on the stunning floor, whereby two held the sheep still, while the third one performed electrical stunning $(650 \mathrm{~V}$ for $60 \mathrm{~s})$ on the sheep. The tongs of the stunner were cone cave in shape and were positioned on the sides of the head above the eye level. During the stunning and exsanguination periods there was no consistency, some animals were double stunned on different positions (e.g. on the sides of the head, then head to jaw if it did not work), some were not exsanguinated immediately (would exceed $60 \mathrm{~s}$ before killing), the stunning or even exsanguination would be done by different workers from animal to animal. The abattoir workers seemed not to ignore the importance of following the standards. The sheep were hung vertically by both hind legs immediately after stunning. Then a sharp knife was used for jugular cutting and initiation of the bleeding process. Due to the manual process used at the abattoir and the small area they work in, only 7 sheep could hang at a time for bleeding and skinning. A batch of seven sheep were stunned, hung, bled and dressed; after all that another batch of seven would be done next.

\section{Behaviour scoring}

Behaviour categories (Table 1) were observed from the introduction of the animals onto the slaughter floor. Records were taken at three stages of slaughter; before stunning, after stunning, and at bleeding; where it was assumed that 
Table 1. Avoidance-related behavioural scores of sheep at slaughter

\begin{tabular}{lc}
\hline Category & Code \\
\hline Before stunning & 1 \\
Standing (rests on four legs)-calm & 2 \\
Sitting (rests on thighs and front legs)-calm but threatened & 2 \\
Other e.g. jumping (unstable/trying to escape/aggression) & 3 \\
After stunning & \\
Stable (no movement)-calm & 1 \\
Kicks before cutting-aggression/panic & 2 \\
Kicks at cutting-aggression/panic & 3 \\
While bleeding & \\
Stable (no movement)-calm & 1 \\
Head/ and tail movement (wagging)-aggression/panic & 2 \\
Kicking (front/hind legs)-aggression/panic & 3 \\
\hline
\end{tabular}

Modified from Terlouw and Porcher (2005).

the higher the response scores assigned the higher the avoidance behaviour. This was done by one person observing and recording on a sheet of paper. The recorder was standing approximately $1.5 \mathrm{~m}$ away from the exsanguination point. The scoring was modified from that described by Terlouw and Porcher (2005).

\section{Bleeding times}

The time interval between the start of the blood flow and the time the flow changed from a constant stream into drips (Kirton and Woods, 1977) was recorded as bleeding times. A stop watch was used for this purpose.

\section{Meat samples preparation}

A total of 32 carcasses were randomly selected and from the longissimus dorsi muscle of these carcasses, meat samples were obtained. The number of meat samples obtained was dependant on the butchery owner slaughtering at the time, who was willing to give out the samples. The loin muscle used for scientific purposes is very expensive and valued by all. These meat samples were cut from the loin muscle the next day (within the $24 \mathrm{~h}$ of slaughter) after chilling at a temperature range of 1 to $4^{\circ} \mathrm{C}$ and were put into small vacuumed plastic bags each.

\section{$\mathrm{pH}_{24}$, temperature $24 \mathrm{~h}$ post-mortem, and colour measurements}

The $\mathrm{pH}$ and temperature at $24 \mathrm{~h}$ post mortem were measured from each of the meat samples using a portable $\mathrm{pH}$ meter (Crison pH 25, Crison instruments, S.A., Alella, Spain). The $\mathrm{pH}$ meter was calibrated once before the readings were taken with $\mathrm{pH} 4$ and $\mathrm{pH} 7$ standard solutions and those records were fitted into a data sheet accordingly. The colour variables $\mathrm{L}^{*}$ (lightness), $\mathrm{a}^{*}$ (redness), $\mathrm{b}^{*}$ (yellowness), were also measured from each of the obtained meat samples using a Minolta colour-guide 45/0 BYK-
Gardener $\mathrm{GmbH}$ machine, with a $20 \mathrm{~mm}$ diameter measurement area and illuminant D65-day light, $10^{\circ}$ observation angle and recorded on a data sheet. The machine was rotated three times on each sample and the average reading was taken. The samples were then vacuum packed and stored in a freezer at a temperature of $-4^{\circ} \mathrm{C}$ to keep them fresh.

\section{Cooking loss and tenderness determination}

The frozen meat samples were taken out of the refrigerator and placed in a tray at room temperature for 12 $\mathrm{h}$ (day before cooking) before the actual experiment (cooking), to allow them to defrost completely on their own. They were then weighed using a PGW 753i Adam weighing scale, and those records were entered into a record sheet. The sample weights ranged between 10 to 20 grams with minimal or no fat cover. The meat samples were put into heat tolerant small plastic bags sealed and labelled accordingly for identification in preparation for cooking. They were cooked using a water bath, with the water heated at a temperature of $85^{\circ} \mathrm{C}$ for $45 \mathrm{~min}$. After cooking, the samples were taken out of the water onto a tray and allowed to cool for $20 \mathrm{~min}$ at room temperature. The raw and cooked weights of the samples were then measured and recorded. Cooking loss was calculated by subtracting the weight before cooking from the weight after cooking, dividing that by the weight before cooking, and multiplying by a hundred, thus the cooking loss percentage.

$$
\begin{aligned}
& \text { Cooking loss (CL)\% } \\
& =\left[\frac{\text { weight before cooking - weight after cooking }}{\text { weight before cooking }}\right] \times 100 \%
\end{aligned}
$$

Mutton tenderness was determined after cooking using the Instron-Warner-Bratzler Shear Force (WBSF). Three sub samples of specified $10 \mathrm{~mm}$ core diameter were cored parallel to the grain of the meat. The samples were sheared perpendicularly to the fibre direction, using a Warner Bratzler (WB) shear device mounted on an Instron (Model 3344) University Testing apparatus (cross head speed at 400 $\mathrm{mm} / \mathrm{min}$, one shear in the centre for each core). The mean maximum load $(\mathrm{N})$ was recorded for the batch.

\section{Statistical analysis}

The data was analysed using SAS (2003). The $x^{2}$ (chi square) test was used to assess the effect of age group, breed, and gender on behavioural scores. Analysis of covariance (ANCOVA) was used to test the effect of animal characteristics (breed, age group, gender) on the bleeding times at exsanguination and meat quality variables, with carcass weight as a covariate. Correlation between the weight of the animal and bleeding times was determined. 
The model used was:

$$
\mathrm{Y}_{\mathrm{ijkl}}=\mu+\alpha_{\mathrm{i}}+\beta_{\mathrm{j}}+\lambda_{\mathrm{k}}+\beta_{1} \mathrm{X}_{1}+\mathrm{e}_{\mathrm{ijkl}}
$$

Where; $\mathrm{Y}_{\mathrm{ijkl}}$ was the bleeding time and meat quality variables; $\mu$ was the overall mean response; $\alpha_{i}$ was the effect of breed (Dorper, Cross, and Merino); $\beta_{\mathrm{j}}$ was the effect of gender (male, and female); $\lambda_{k}$ was the effect of age group ( $<10$ months, 11 to 12 months); $\beta_{1} X_{1}$ was the effect of weight and $\mathrm{e}_{\mathrm{ijkl}}$ was the experimental error. The data was analysed as an unbalanced treatment. Correlations between bleeding times and meat quality of slaughtered sheep were determined.

\section{RESULTS AND DISCUSSION}

Visual observations of the abattoir characteristics and their possible effects on avoidance-related behaviour, bleeding times and meat quality of sheep

The abattoir was characterised by an offloading area, holding pens (lairage), a crush connecting the lairage to the slaughter house, and the actual slaughter house with two rooms. The floors of these facilities were concrete. All the operations performed at the abattoirs were divided among these facilities. Sheep were manually offloaded into the lairage and were manually driven through the crush within an hour of arrival for slaughter. The stunning process was performed in the same room where bleeding, skinning and carcass dressing was done in different sides of the room. For the purpose of stunning, sheep were held down on the concrete floor by either one or two abattoir workers just to prevent them from escaping. This was thought to have an impact on the behaviour of the animals at this point as animals were trying to escape, jumping around making it difficult to handle them. These observations concur with a report by Gonyou (1997) that cornered sheep showed avoidance behaviour such as hoof stamping and aggressive posture.

Following stunning, the sheep were hoisted on a nonmoving rail by their hind legs using chains and the vertical bleeding process was initiated. This process was achieved by cutting through the neck of the animal and splitting open the jugular vein. This process used in this abattoir is perceived to be hygienic compared to the horizontal process which brings about faster bleeding rate (RMAA, 2011). Due to the low numbers of animals slaughtered in this abattoir, carcasses were not rushed into the coolers so as to open space for more animals. Instead the carcasses were left hanging on their hind legs even after dressing. This is believed by the abattoir staff to allow more time for the blood drops to drain off the carcass. However; even though this is an approved structure for the "rural abattoirs"
Table 2. Effects of age group, breed and gender on animal behaviour before, after stunning, and during bleeding

\begin{tabular}{|c|c|c|c|}
\hline$\overline{\text { Parameters }}$ & BBS & BAS & $\mathrm{BAB}$ \\
\hline & \multicolumn{3}{|c|}{ 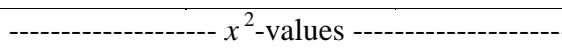 } \\
\hline Breed & $22.4 * *$ & $7.3^{\mathrm{NS}}$ & $41.7 * *$ \\
\hline Age group & $15.9 * *$ & $6.3^{*}$ & $27.3 * *$ \\
\hline Gender & $1.6^{\mathrm{NS}}$ & $7.4^{*}$ & $10.7 *$ \\
\hline $\begin{array}{l}\text { BBS = Beh } \\
\text { BAB = Beha } \\
* * p<0.001 \mathrm{~s} \\
\mathrm{NS}=\text { Not sig }\end{array}$ & $\begin{array}{l}\text { efore stunn } \\
\text { ring bleedin } \\
\text { t level, * p } \\
\text { at any level, }\end{array}$ & $\begin{array}{l}\text { icant } \\
\text { quare }\end{array}$ & fter stu \\
\hline
\end{tabular}

(RMAA, 2011), performing all the slaughter processes (both dirty and clean) in one room could end up contaminating the meat, thus reduced meat quality. Another possible contamination with microbial spoilage was prone to be a problem at the current abattoir due to prolonged periods of more than sixty seconds before the animals were bled. Lawrie and Ledward (2006) reported that bleeding be performed as soon as possible following stunning to minimise such problems.

\section{Animal avoidance-related behaviour at slaughter}

Animal behaviour at slaughter differed with breed, gender and age group (Table 2). Hemsworth and Coleman (1998) reported that animal exposure to human beings and to sudden changes in their social or physical environments is a frightening event. This was the case when animals were being introduced to the slaughter floor. They showed signs of panic and wanting to escape. The primary defense mechanism for sheep is simply to flee from danger when their flight zone is crossed. Cornered sheep may charge or threaten to do so through hoof stamping and aggressive posture (Gonyou, 1997).

The behaviour differences by age and gender after stunning were of no surprise even though stunning brings about unconsciousness. The RMAA (2011) reported that even though a properly stunned animal should be unconscious, paddling movements of the feet may occur. However, Ndou et al. (2011) reported that low-through put abattoirs are known to operate under less genial conditions with poor handling facilities and inexperienced, ignorant workers or handlers. A better grasp of the situation was evidenced when some of the animals were double stunned due to ineffective initial stunning with some left for longer periods (>60 s) before exsanguination by which resumption of consciousness was possible. Hence these behaviour responses may have had nothing to do with the type of breed, age nor gender of the animal, but the stunning operations at the slaughter house conditions/procedures. However, McKinstry and Anil (2004) reported that double stunning pigs did not affect their welfare, even though it should be avoided. 


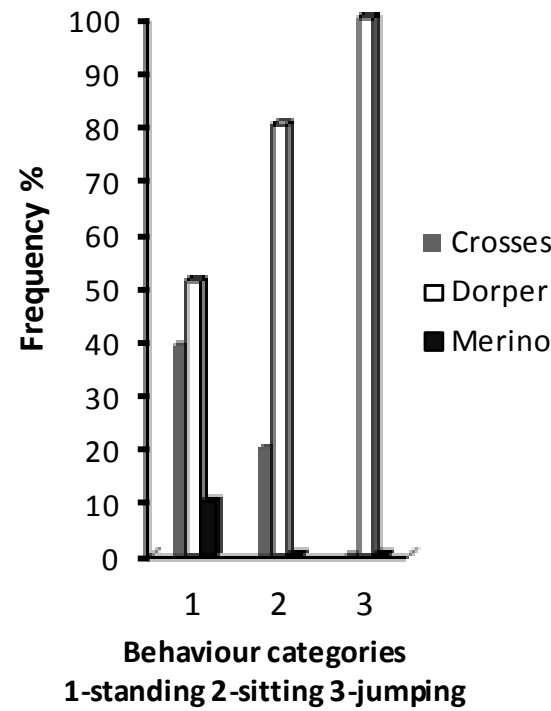

(a)

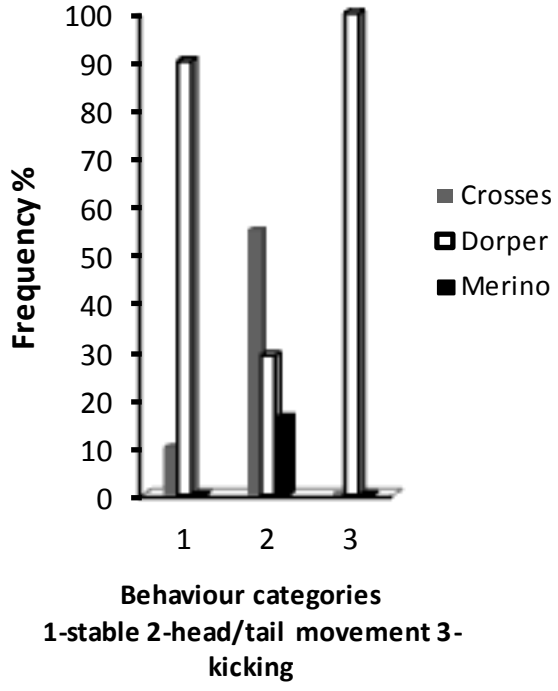

(b)

Figure 1. Frequencies of breeds in animal avoidance-related behaviour categories before stunning and during bleeding.

In Figure 1, the Dorper breed dominating all the behaviour categories, increasing in numbers with increased behaviour scores. The Merino breed and Dorper+Merino crosses were calm than Merino breed. The Merino breed is described as calm in its nature (Paterson, 1990). Results in this study show signs of aggression with the Dorper and the reason for this is not fully understood because it is also regarded as a calm breed. However these results may have had nothing to do with the breed per se but other factors like the abattoir influence. In an arena study on lambs, it was found that Berrichon-du-Cher cross lambs were more active compared to the parent breeds, with high counts of attempts to escape the test (Boissy et al., 2005). However in the current study, the Dorper+Merino cross lambs were calmer than the Dorper breed. The calm nature shown by the Dorper+Merino cross lambs could be because of crossing two calm breeds in nature (Dodd et al., 2012).

Younger animals ( $<10$ months) dominated all the behaviour categories increasing with increasing scores (Figure 2). The older animals were mostly calm. Similar results were obtained in a study by Vierin and Bouisson (2003). Older animals have been exposed to many different stressful situations before such that they are able to cope better with similar encounters (Lambe et al., 2001; Dodd et al., 2012).

Castrates were more relaxed before stunning compared to ewes (Figure 3). Strappini et al. (2010) reported that in some arena tests, rams were observed to be less fearful than ewes. However, during bleeding ewes were more relaxed with castrates showing aggressive behaviour. This change of behaviour between the two genders in these stages of slaughter is not understood.

\section{Bleeding times at exsanguination}

Bleeding times did not differ with breed and age group (Table 3). Castrates took longer ( $72.6 \pm 0.53 \mathrm{~s})$ to bleed than ewes $(63.6 \pm 2.82 \mathrm{~s})$. The current results contradict those obtained in an earlier study (Njisane, 2012) on sheep slaughtered at a commercial abattoir and the reason for this is not fully understood. In another study older sheep (>12 months) had longer (67.5 $\pm 1.82 \mathrm{~s})$ bleeding times compared to lambs (Njisane and Muchenje, 2013). Bourguet et al. (2011) reported that abattoir operations differ greatly, with low throughput abattoirs using poor handling facilities (Kadim et al., 2007; Gregory, 2008; Strappini et al., 2010). Moreover, animals' reactions differ when subjected to different handling techniques (Grandin, 1990). Figure 3b of the current study showed that castrates were aggressive during the bleeding process. This could have been a result of handling before and during exsanguination resulting in muscles and blood vein contraction such that the blood passages were blocked, causing a delay. There was no correlation between the weight of the animal and bleeding times. As in the previous study, the use of carcass weights as a covariate might have had an effect on bleeding times results. Bleeding times did not differ with age group and breed.

\section{Meat quality}

The quality of meat did not differ with breed, age class and the behaviour of the animals at slaughter. The results in Table 4 show that meat colour variables $\mathrm{L}^{*}, \mathrm{a}^{*}$, and $\mathrm{b}^{*}$ were not affected by gender differences. However, meat from ewes $(39.8 \pm 1.04 \%)$ had higher $(\mathrm{p}<0.001)$ cooking losses than meat from castrates $(35.1 \pm 0.95 \%)$. This can be linked 


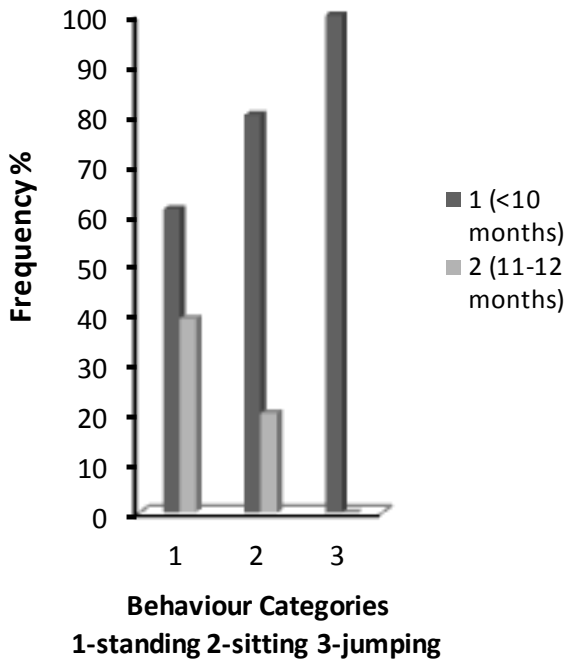

(a)

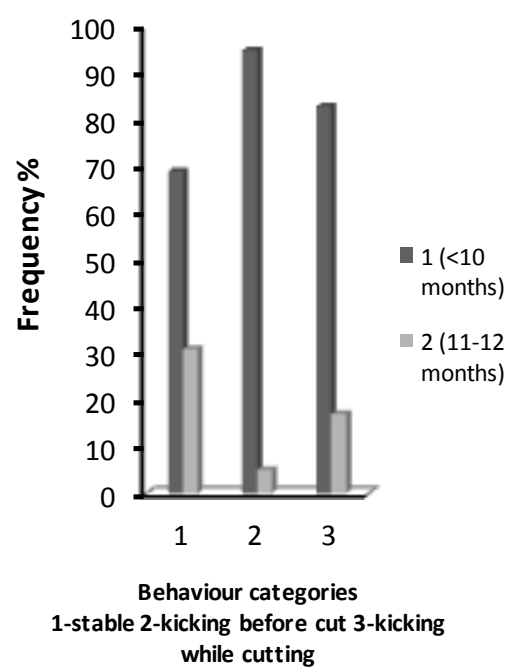

(b)

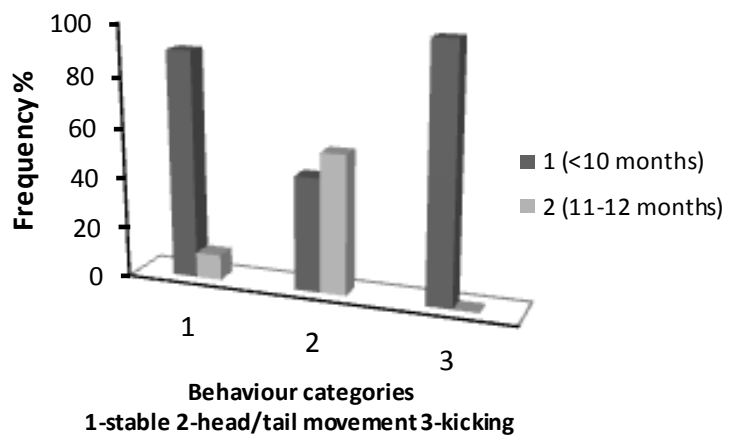

(c)

Figure 2. Frequencies of age groups in animal avoidance-related behaviour categories before and after stunning, and during bleeding.

to the extra production role played by the female animals in reproduction compared to males thus reduced muscle water holding capacity (Malterre and Jones, 1992). These results concur with the results obtained earlier in Njisane (2012). In a study on cattle, meat quality and palatability declined with increase in animal maturity and parity (Malterre and Jones, 1992). Castrates from the current study produced tougher meat $(32.6 \pm 1.95 \mathrm{~N})$ compared to ewes $(24.3 \pm 1.16 \mathrm{~N})$, while

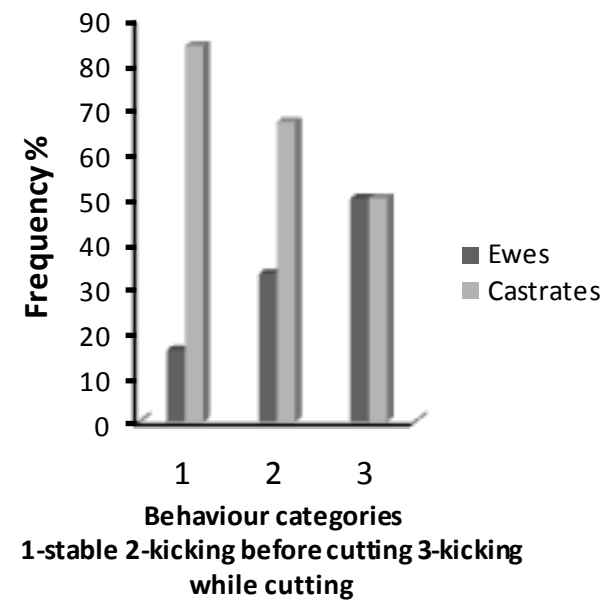

(a)

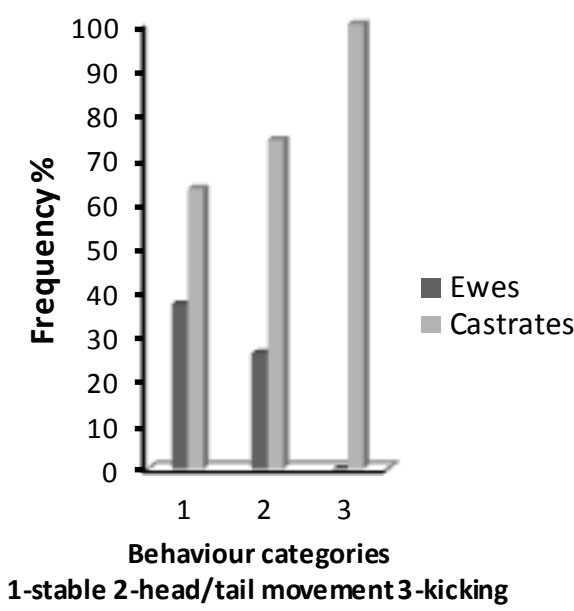

(b)

Figure 3. Frequencies of gender in animal avoidance-related behaviour categories after stunning and during bleeding. 
Table 3. The effect of age group, breed, and gender on bleeding time scores ( \pm SEM) of animals at slaughter

\begin{tabular}{llcc}
\hline Variables & \multicolumn{1}{c}{ Classes } & Mean $( \pm$ SE $)$ & Significance level \\
\hline Age group & $1(<10$ months $)$ & $69.5 \pm 1.84$ & NS \\
& $2(11-12$ months $)$ & $74.2 \pm 3.02$ & \\
\multirow{2}{*}{ Breed } & Crosses & $74.2 \pm 3.02$ & NS \\
& Dorper & $70.2 \pm 1.80$ & $60.8 \pm 10.65$ \\
Merino & Ewes & $63.6 \pm 2.82^{\mathrm{b}}$ & $* *$ \\
\hline
\end{tabular}

Means in the same row with different superscripts are significantly different at $\mathrm{p}<0.05$

$* * \mathrm{p}<0.001$ significant level. $* \mathrm{p}<0.05$ significant level. NS $=$ Not significant at any level.

Table 4. The effect of animal gender on the colour $\left(\mathrm{L}^{*} \mathrm{a}^{*} \mathrm{~b}\right)$, cooking loss and tenderness of mutton

\begin{tabular}{lccc}
\hline Parameters & Ewes (LSmean \pm SEM) & Castrates (LSmean \pm SEM) & Significance \\
\hline $\mathrm{N}$ & 7 & 25 & $\mathrm{NS}$ \\
Lightness $\left(\mathrm{L}^{*}\right)$ & $36.5 \pm 1.80$ & $35.2 \pm 1.23$ & $\mathrm{NS}$ \\
Redness $\left(\mathrm{a}^{*}\right)$ & $18.8 \pm 0.39$ & $16.7 \pm 0.49$ & $\mathrm{NS}$ \\
Yellowness $\left(\mathrm{b}^{*}\right)$ & $13.0 \pm 0.99$ & $10.9 \pm 0.51$ & $* *$ \\
Cooking loss $(\%)$ & $39.8^{\mathrm{a}} \pm 1.04$ & $35.1^{\mathrm{b}} \pm 0.95$ & $*$ \\
WBSF $(\mathrm{N})$ & $24.3^{\mathrm{b}} \pm 1.16$ & $32.6^{\mathrm{a}} \pm 1.95$ & $*$ \\
\hline
\end{tabular}

Means in the same row with different superscripts are significantly different at $\mathrm{p}<0.05$.

NS $=$ Not significant. $* \mathrm{p}<0.05, * * \mathrm{p}<0.001 . \mathrm{WBSF}=$ Warner Bratzler Shear Force for meat Tenderness

there were no differences between genders from the earlier study in a commercial abattoir (Njisane, 2012). In a study on deer, female deer had $32 \%$ more intramuscular fat with more tender meat compared to male deer who also produced tougher meat (Goosen et al., 1999). Intramuscular fat improves the tenderness of the meat (Agbeniga, 2012). The current study contradicts the study by Wheeler et al. (1998) which implied that meat that loses more water is tougher than meat that loses less water. In this study, meat from ewes had a higher cooking loss and lower WBSF values than meat from castrates. There were no significant correlations $(p>0.05)$ between bleeding times and meat quality traits. The meat quality traits were also not correlated. This may have been influenced by the small number of meat samples that were obtained from the butcheries during the trial.

\section{CONCLUSIONS}

Abattoir conditions/ or procedures, the breed of the animal, age class/ or group and gender had an effect on the behaviour of sheep at slaughter. Gender also had an effect on bleeding times and the quality of mutton. Correlations did not exist between bleeding times and meat quality traits, and among the mutton quality traits.

\section{ACKNOWLEDGEMENTS}

The authors would like to acknowledge the Red Meat
Research and Development Trust (Meat Industry Trust) and the NRF-RMRD-SA THRIP Project (T113), the abattoir and butcheries that took part.

\section{REFERENCES}

Agbeniga, B. 2012. Influence of Conventional and Korsher slaughter techniques in cattle on carcass and meat quality. MSc Agriculture (Meat Science) thesis. University of Pretoria, South Africa. www.netd.ac.za. Accessed: 28 September 2012.

Ahnstrom, M. L., M. C. Humt, and K. Lundstrom. 2012. Effects of pelvic suspension of beef carcasses on quality and physical traits of five muscles from four gender-age groups. Meat Sci. 90:528-535.

Boissy A., J. Bouix, P. Orgeur, P. Poindron, B. Bibe, and P. Le Neindre. 2005. Genetic analysis of emotional reactivity in sheep: effects of genotypes of the lambs and of their dams. Gen. Sel. Evol. 37:381-401.

Boivin, X., R. Nowak, P. Le Neindre, H. Tournadre, and P. Le Neindre. 1997. Discrimination between shepherds by lambs reared under artificial conditions. J. Anim. Sci. 75:2892-2898.

Bourguet, C., V. Deiss, C. C. Tannugi, and E. M. C. Terlouw. 2011. Behavioural and physiological reactions of cattle in a commercial abattoir: Relationships with organisational aspects of the abattoir and animal characteristics. Meat Sci. 88:158168.

Breuer, K., P. H. Heemsworth, J. L. Barnett, L. R. Mathews, and G. J. Coleman. 2000. Behavioural response to humans and productivity of commercial dairy cows. Appl. Anim. Behav. Sci. 66:273-288.

Dodd, C. L., W. S. Pitchford, J. E. H. Edwards, and S. J. Hazel. 2012. Measures of behavioural reactivity and their 
relationships with production traits in sheep: A review. Appl. Anim. Behav. Sci. 140:1-15.

Dodzi, M. S. and V. Muchenje. 2011. Avoidance-related behavioural variables and their relationship to milk yield in pasture-based dairy cows. Appl. Anim. Behav. Sci. 133:11-17.

Dorper Sheep Breeders' Society of South Africa. A report by Henry du Plooy, Kiewietskloof, Griekwastad 8365, Northern Cape, South Africa. www.ansi.okstate.edu. Accessed: 22 February 2012.

Gonyou, H. W. 1997. Sheep and goats. In: Animal welfare issues compendium (Ed. R. D. Reynnells and B. R. Eastwood). Pages 118-124.

Goosen, G. J., P. F. Fennessy, and A. J. Pearse. 1999. Carcass composition comparison of male and female red deer and hybrids with Pere David's deer. NZ. J. Agric. Res. 42:483-491.

Grandin, T. 1980. Observations of cattle behaviour applied to the design of cattle handling facilities. Appl. Anim. Behav. Sci. 6:19-31.

Grandin, T. 1990. Design of loading facilities and holding pens. Appl. Anim. Behav. Sci. 28:187-201.

Grandin, T. 1996. Factors that impede animal movement at slaughter plants. J. Am. Vet. Med. Assoc. 209:757-759.

Grandin, T. 2002. Good management practices for animal handling at stunning, second edition. American meat institute, Washington DC, USA.

Grandin, T. 2003. Transferring results of behavioural research to industry to improve animal welfare on the farm, ranch and slaughter plant. Appl. Anim. Behav. Sci. 81:215-228.

Grandin, T. 2006. Progress and challenges in animal handling and slaughter in the US: Sentience in Animals. Appl. Anim. Behav. Sci. 100:129-139.

Grandin, T. 2010. Auditing animal welfare at slaughter plants. Meat Sci. 86:56-65.

Gregory, N. G. 2008. Animal welfare at markets and during transport and slaughter. Meat Sci. 80:2-11.

Hemsworth, P. H. 2003. Human-Animal interactions in livestock production. Appl. Anim. Behav. Sci. 81:185-198.

Hemsworth, P. H. and G. J. Coleman. 1998. Human-Livestock interactions. In: The stockperson and the productivity of intensively farmed animals. CAB International Wallingford.

Hemsworth, P. H., J. L. Barnett, and C. Hansen. 1987. The influence of consistent handling by humans on the behaviour, growth and corticosteroids of young pigs. Appl. Anim. Behav. Sci. 17:245-252.

Jago, J. G., A. L. Hargreaves, R. G. Harcourt, and L. R. Mathews. 1996. Risk factors associated with bruising in Red Deer at a commercial slaughter plant. Meat Sci. 44:181-191.

Kadim, I. T., O. Mahgoub, A. Y. Al-Kindi, W. Al-Marzooqi, N. AlSaqri, M. Almaney, and I. Y. Mahmoud. 2007. Effect of transportation at high ambient temperatures on physiological responses, carcass and meat quality characteristics in two age groups of Omani sheep. Asian-Aust. J. Anim. Sci. 20:424-431.

Kirton, A. H. and E. G. Woods. 1977. Blood weights, bleeding times of electrically stunned sheep slaughtered by three different procedures. N. Z. J. Agric. Res. 20:449-451.

Lambe, N. R., J. Conington, S. C. Bishop, A. Waterhouse, and G. Simm. 2001. A genetic analysis of maternal behaviour score in Scottish Blackface sheep. J. Anim. Sci. 72:415-425.

Lawrie, R. D. and D. A. Ledward. 2006. Lawrie's Meat Science.
Seventh edition. Woodhead Publications, Cambridge, England. Malterre, C. and S. D. M. Jones. 1992. Meat production from heifers and cull cows. In: World Animal Science. C production system approach, 5 beef cattle production (Ed. R. Jarrige and C. Beranger). Elsevier, Amsterdam, pp. 357-375.

Markowitz, T. M., M. R. Dally, K. Gursky, and E. O. Price. 1998. Early handling increases lamb affinity for humans. Appl. Anim. Behav. Sci. 55:573-587.

McGreevy, P. 2003. Notes on some topics in applied animal behaviour. In: Chapter 5, Design of facilities for management of livestock. www.animalbehaviour.net. Accessed: 17 January 2012.

McKinstry, J. L. and M. H. Anil. 2004. The effect of repeat application of electrical stunning on the welfare of pigs. Meat Sci. 67:121-128.

Ndou, S. P., V. Muchenje, and M. Chimonyo. 2011. Assessment and implications of animal welfare in beef production systems in developing countries. African J. Biotech. 10:1049-1064.

Njisane, Y. Z. 2012. Avoidance-related behaviour, bleeding times and the quality of meat from sheep slaughtered at a commercial and a municipal abattoir. MSc Agriculture Dissertation. University of Fort Hare, Alice, South Africa.

Njisane, Y. Z. and V. Muchenje. 2013. Quantifying avoidancerelated behaviour and bleeding times of sheep of different ages, sex and breeds slaughtered at a municipal and a commercial abattoirs. S. Afr. J. Anim. Sci. 43:38-42.

Paterson, M. 1990. National Merino review. West Perth, Australia: Farmgate Press. pp. 12-17. ISSN 1033-5811.

Red Meat Abattoir Association (RMAA). 2011. Animal handling practical guidelines for abattoirs.

Roca, R. O. 2002. Humane slaughter of bovine; First Virtual Global Conference on Organic Beef cattle Production. 02 September -15 October 2002.

SAS. 2003. SAS/STAT Software Release 6.12. SAS Institute Inc., Cary, NC, USA.

Strappini, A. C., K. Frankena, J. H. M. Metz, C. B. Gallo, and B. Kemp. 2010. Prevalence and risk factors for bruises in Chileon bovine carcasses. Meat Sci. 86:859-864.

Swatland, H. J. 2000. Slaughtering. Internet: http://bert.aps. uoguelph.ca/swatland/ch1.9.htm. p 10. Accessed: 18 February 2013.

Terlouw, E. M. C. and J. Porcher. 2005. Repeated handling of pigs during rearing. I. Refusal of contact the handler and reactivity to familiar and unfamiliar humans. J. Anim. Sci. 83:1653-1663.

Vierin, M. and M. F. Bouisson. 2003. Responses of weaned lambs to fear eliciting situations: origin of individual differences. Dev. Psychobiol. 42:131-147.

Waiblinger, S., X. Boivin, V. Pedersen, M.V. Tosi, A.M. Janczak, E. K. Visser, and R. B. Jones. 2006. Assessing the human-animal relationship in farmed species: A critical review. Appl. Anim. Behav. Sci. 101: 185-242.

Wheeler, T. L., S. D. Shackelford, and M. Koohmaraie. 1998. Cooking and palatability traits of beef longissimus steaks cooked with a belt grill or an open hearth electric broiler. J. Anim. Sci. 76:2805-2810.

Wood, J. D., R. L. Richardson, G. R. Nute, A. V. Fisher, M. M. Campo, E. Kasapidou. 2003. Effect of acid on meat quality: A review. Meat Sci. 66:21-32. 